Document downloaded from:

http://hdl.handle.net/10251/98410

This paper must be cited as:

Cesar Leonardo Trujillo Rodríguez; Velasco De La Fuente, D.; Figueres Amorós, E.; Garcerá, G. (2010). Analysis of active islanding detection methods for grid-connected microinverters for renewable energy processing. Applied Energy. 87(11):3591-3605. doi:10.1016/j.apenergy.2010.05.014

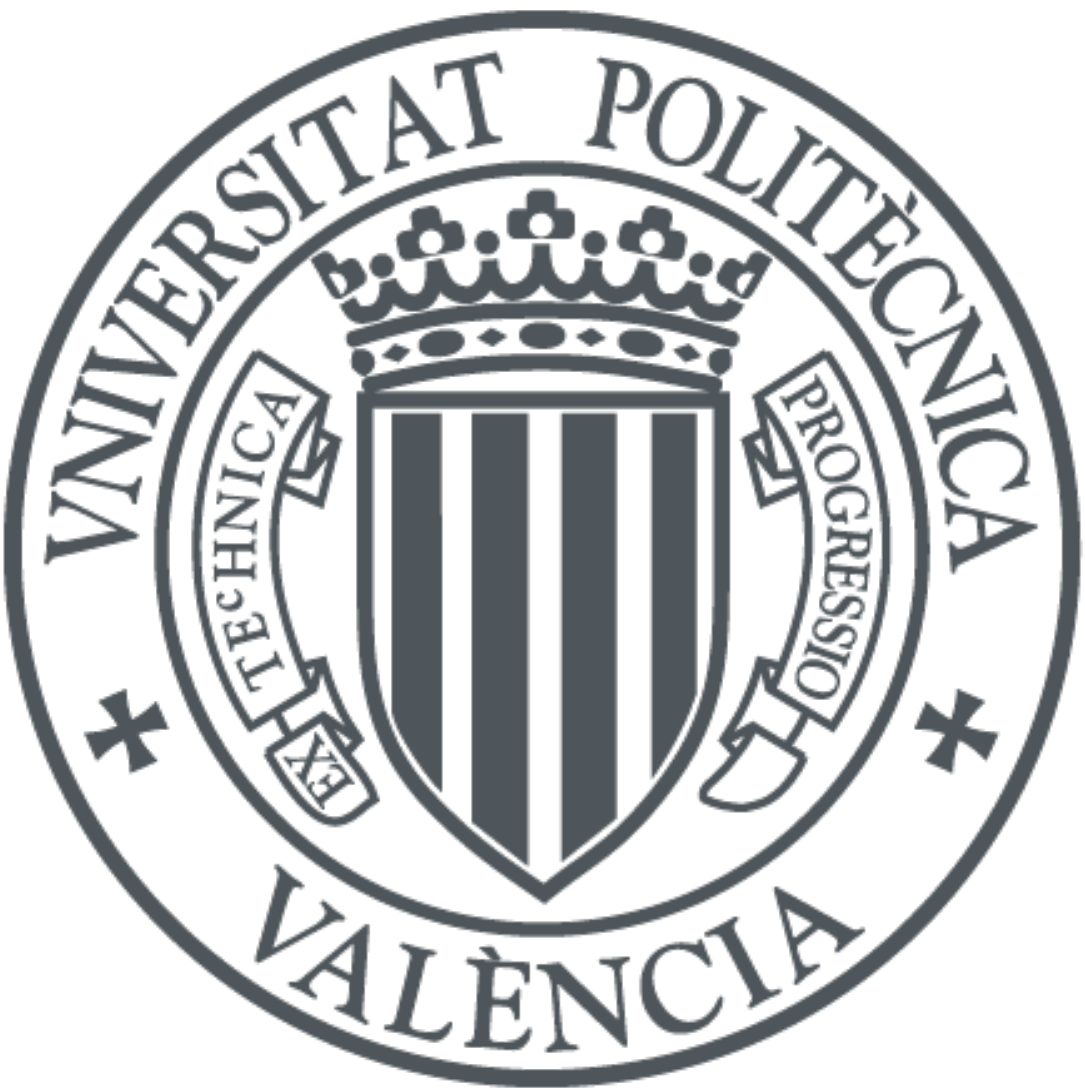

The final publication is available at

https://doi.org/10.1016/j.apenergy.2010.05.014

Copyright Elsevier

Additional Information 


\title{
Analysis of Active Islanding Detection Methods for Grid-Connected Microinverters for Renewable Energy Processing
}

\author{
C.L. Trujillo ${ }^{1,2}$, D. Velasco ${ }^{1}$, E. Figueres ${ }^{1}$, G. Garcerá ${ }^{1}$ \\ ${ }^{1}$ Grupo de Sistemas Electrónicos Industriales del Departamento de Ingeniería Electrónica, \\ Universidad Politécnica de Valencia, Camino de Vera S/N, C.P. 46022, Valencia, Spain, \\ http://www.gsei.upv.es, e-mail: davede@posgrado.upv.es, efiguere@eln.upv.es, ggarcera@eln.upv.es \\ ${ }^{2}$ Departamento de Ingeniería Electrónica, Universidad Distrital Francisco José de Caldas, Carrera 7 \\ No 40-53 Piso 5, Bogotá, Colombia, e-mail: cltrujillo@udistrital.edu.co
}

\begin{abstract}
This paper presents the analysis and comparison of the main active techniques for islanding detection used in grid-connected microinverters for power processing of renewable energy sources. These techniques can be classified into two classes: techniques introducing positive feedback in the control of the inverter and techniques based on harmonics injection. Accurate $\mathrm{PSIM}^{\mathrm{TM}}$ simulations have been carried out in order to perform a comparative analysis of the techniques under study and to establish their advantages and disadvantages according to IEEE standards.
\end{abstract}

Keywords: Distributed Generation, Renewable Energy Sources, Microinverters, Active Islanding Detection Methods.

\section{Introduction}

In recent years, a major global priority is the development of renewable energy. These energy sources produce lower pollution in terms of $\mathrm{CO} 2$ emissions than conventional fossil fuels. From this point of view the distributed generation concept takes importance and it represents a paradigm shift from centralized power generation [1-2].

Distributed generation can be defined as small-scale generators installed near the loads with the ability of interacting with the grid importing or exporting energy [3].

Under this scheme, autonomous low power converters called microinverters [4] have been developed. The microinverters have the ability of operating both in grid connected mode by injecting energy from renewable sources (solar energy, wind energy, fuel cells, among others) to the grid, and in islanding mode feeding local loads without grid connection. Besides, they can be connected to other inverters with similar characteristics to supply a higher number of loads, being easy to expand [5-6].

When a Distributed Generator (DG) is injecting power to the grid, one feature that should be taken into account is the islanding condition. The condition of "Islanding" in DGs is an electrical phenomenon that occurs when the energy supplied by the power grid is interrupted due to various factors and the DGs continue energizing some or the entire load. Thus, the power grid stops controlling this isolated part of the distribution system, which contains both loads and generation. Therefore, islanding operation of grid connected inverters may compromise security, restoration of service and the reliability of the equipment [7].

In the case of several DGs connected to a low-voltage power grid, it is possible that the amount of energy generated by the distributed system agrees with the amount of energy consumed by the loads on the grid. Under this situation, there is no energy flow towards the 
grid and the distributed systems may fail to detect a possible power grid disconnection, so that the DGs may continue feeding the loads leading to an "Islanding" condition. In addition, when the islanding condition happens, there is a primary security condition which forces the generator system to disconnect from the de-energized grid without taking into account the connected loads.

The "islanding" effect in inverters may result from a failure detected by the grid and the consequent switch opening, accidental opening of the electrical supply because of equipment failure, sudden changes in the electric distribution systems and loads, intentional disconnection for maintenance services either on the network or in the service, human error, vandalism or acts of nature.

There are many reasons why islanding should be anticipated in the distributed generation systems connected to the grid. The main reasons are safety, liability and maintenance of the quality of the supplied energy.

For the above reasons, islanding detection is an indispensable feature that should be taken into account in Distributed Generation Systems and different algorithms have been proposed in the last few years to solve it.

Islanding detection techniques can be divided into remote and local ones, and also into passive and active techniques [8]. Active techniques resident in the inverter, which are discussed in this article, introduce disturbances in the output of the inverter in order to affect a certain parameter that comes out of range in an islanding situation.

There are different active methods based on positive feedback in published literature [8], [910]. Some of these methods are: variation of active and reactive power [11], Sandia Voltage Shift (SVS) and Sandia Frequency Shift [12-13], Slip-mode Frequency Shift (SMS) [14], Active Frequency Drift (AFD) [15], and General Electric Frequency Schemes (GEFS) [16], among others.

The paper is organized as follows. First, the grid connected microinverter used to perform the study will be described. Second, different active resident methods will be presented. Next, these methods will be evaluated with RLC loads according to the standards. Finally, some conclusions will be presented.

\section{Description of the Microinverter System}

Fig. 1 shows the scheme of the microinverter that has been used to evaluate the islanding detection algorithms. It is fed by two parallel connected $220 \mathrm{~W}$ photovoltaic panels. The panels voltage is in the range $26-36.7 \mathrm{~V}$ in the maximum power point (MPP), so that a DC-DC stage is needed to raise the voltage supplied by the panels to suitable levels (400V) for grid connection of the power processing system. The power stage chosen for this purpose is a Push-pull DC-DC converter. For DC-AC conversion a current-controlled $\mathrm{H}$-bridge bipolar PWM inverter [17] with an output LCL filter [18-19] has been chosen. Note that the use of a push-pull topology provides galvanic isolation without the need of bulky and heavy low frequency transformers. 


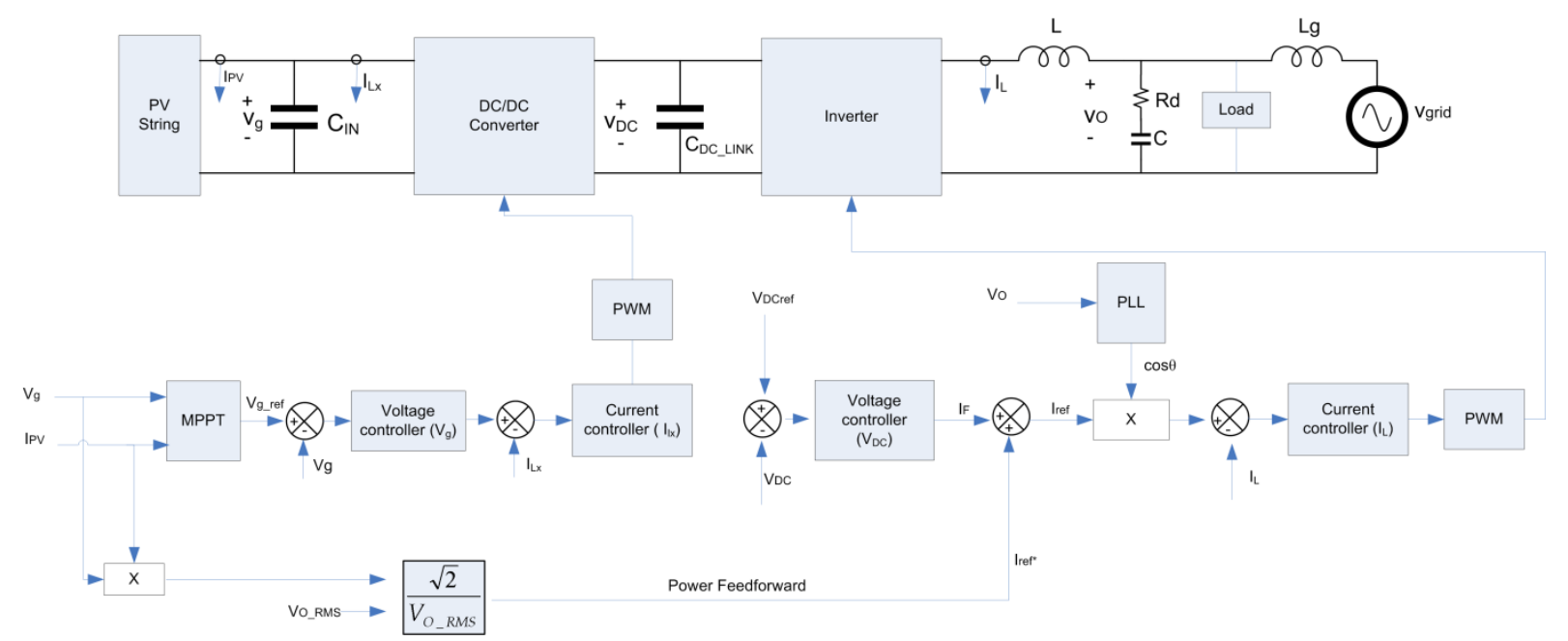

Fig. 1. Block diagram of the microinverter.

As it can be observed from Figure 1, the control of the Push-pull converter starts from a maximum power point tracker (MPPT), implemented by a P\&O (perturb and observe) algorithm [20-22]. The output of the MPPT, $V_{g_{\_} r e f}$, is the reference of the PV string voltage, $V_{g}$. The error between both signals is amplified by a PI voltage controller whose output is the control voltage, $V_{c}$, of the peak current mode control loop (CIC) [23]. This control voltage limits the peak value of the current through the primary of the push-pull transformer, avoiding its saturation. In the peak current mode control PWM modulator an external stabilization ramp, $S_{e}$, is added to the sensed transformer current $\left(S_{n}\right)$. $F_{M}$ is the PWM modulator gain; this value should be adjusted properly in order to guarantee the stability of the current loop. Figure 2 shows the aspect of a conventional CIC loop applied to a push-pull converter.

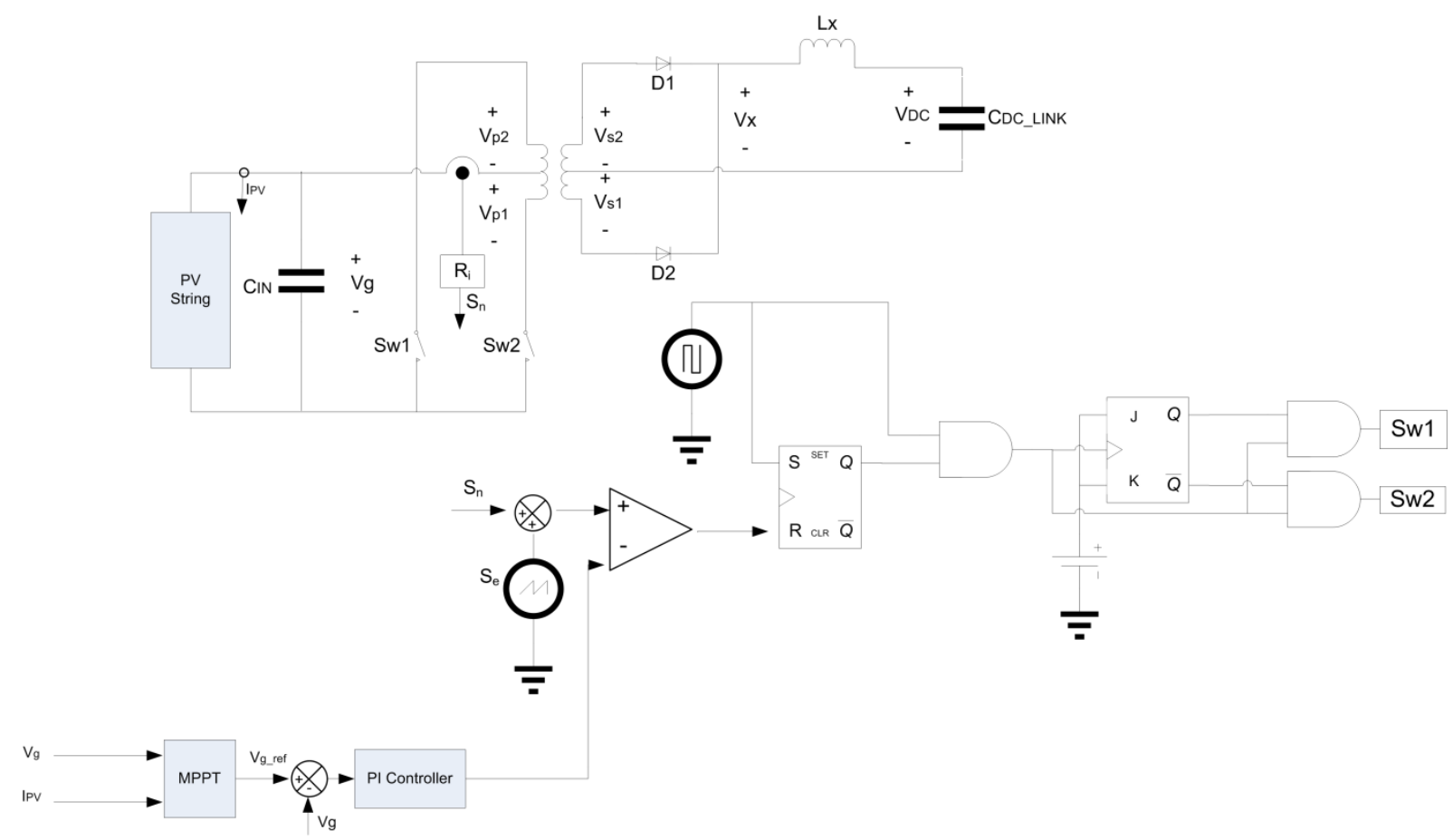

Fig. 2. Conventional $\mathrm{ClC}$ scheme of push-pull converter.

The PWM inverter has an inner current controller based on a harmonic compensator [24] in order to comply with the IEEE 929-2000 standard [25], in terms of the THD of the current injected to the grid. The reference of the current loop is made of the sum of two terms: a 
power-feedforward term used to achieve a fast response of the inverter control with regard to changes in the power generated by the panels [26], and the output of the PI controller of the inverter DC_link voltage. The resulting sum is the amplitude of the inverter reference current, that is synchronized with the fundamental component of the grid voltage by means of a phase locked loop (dqPLL) implemented using the synchronous rotating reference frame technique [27-28]. Figure 3 shows the dqPLL block diagram.

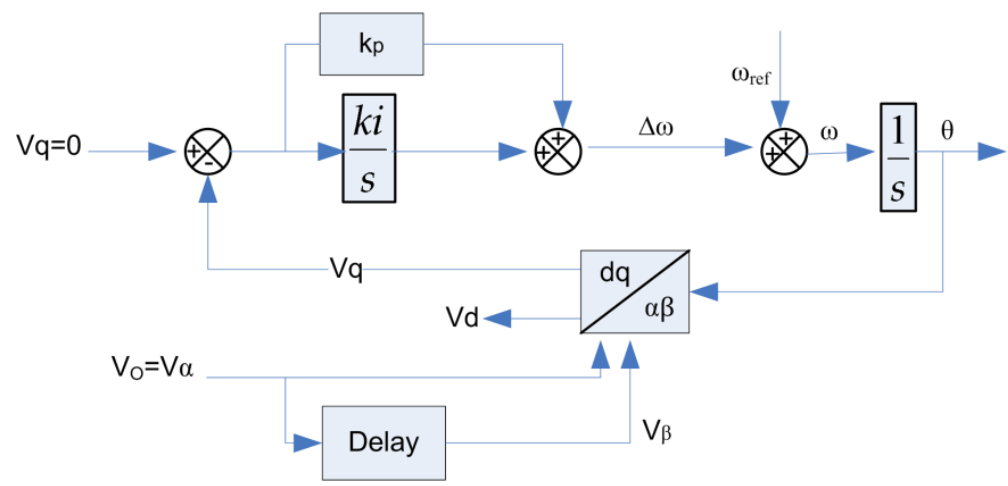

Fig. 3. Block diagram of the dqPLL.

Table 1 summarizes the nominal values of the microinverter.

Table 1. Parameters of the Microinverter Under Study

\begin{tabular}{lc}
\hline \multicolumn{1}{c}{ Parameter } & Values \\
\hline Panel voltage variation $\left(\mathrm{V}_{\mathrm{g}}\right)$ & {$[24 \mathrm{~V}-36.7 \mathrm{~V}]$} \\
Injected power by panel $\left(\mathrm{P}_{\mathrm{pv}}\right)$ & $430 \mathrm{~W}$ \\
DC_LINK voltage $\left(\mathrm{V}_{\mathrm{DC}}\right)$ & $400 \mathrm{~V}$ \\
Inverter output voltage $\left(\mathrm{V}_{\mathrm{O}}\right)$ & $230 \mathrm{~V}_{\mathrm{RMS}}$ \\
Inverter output frequency $\left(\mathrm{f}_{\mathrm{g}}\right)$ & $50 \mathrm{~Hz}$ \\
Push-pull inductance $\left(\mathrm{L}_{\mathrm{x}}\right)$ & $11 \mathrm{mH}$ \\
Push-pull input capacitor $\left(\mathrm{C}_{\mathrm{IN}}\right)$ & $470 \mu \mathrm{F}$ \\
Push-pull transformer turns ratio $(\mathrm{N})$ & 20 \\
Push-pull switching frequency $\left(\mathrm{f}_{\mathrm{s}}\right)$ & $20 \mathrm{kHz}$ \\
DC_LINK capacitor $\left(\mathrm{C}_{\mathrm{DC}} \mathrm{LINK}\right)$ & $1 \mathrm{mF}$ \\
Inverter inductance $\left(\mathrm{L}_{\mathrm{N}}\right)$ & $19.1 \mathrm{mH}$ \\
Inverter output capacitor $(\mathrm{C})$ & $600 \mathrm{nF}$ \\
Damping resistance $\left(\mathrm{R}_{\mathrm{d}}\right)$ & $50 \Omega$ \\
Grid inductance $\left(\mathrm{L}_{\mathrm{g}}\right)$ & $1.91 \mathrm{mH}$ \\
Inverter switching frequency $\left(\mathrm{f}_{\mathrm{si}}\right)$ & $20 \mathrm{kHz}$ \\
\hline
\end{tabular}

Table 2 shows the expression of the chosen regulators for both the inner current loops and the outer loop, crossover frequencies and phase margins, for the microinverter studied.

Table 2. Summary of the Expressions of the Chosen Regulators, Crossover Frequencies and Phase Margins Push-pull

\begin{tabular}{cccc}
\hline Controller & Expression in the continuous time & $\begin{array}{c}\text { Crossover } \\
\text { frequencies }\end{array}$ & $\begin{array}{c}\text { Phase } \\
\text { margins }\end{array}$ \\
\hline $\begin{array}{c}\text { PWM modulator } \\
\text { gain } \\
\text { Voltage controller }\end{array}$ & $F_{M}=\frac{1}{\left(S_{n}+S_{e}\right) \cdot T_{s}}=\frac{1}{(2181+30533) \cdot 50 \mu}$ & $2.63 \mathrm{kHz}$ & $66.4^{\circ}$ \\
$k_{p}+\frac{k_{i}}{s}=1.5+\frac{300}{s}$ & $98.4 \mathrm{~Hz}$ & $89.6^{\circ}$ \\
\hline & Inverter & & \\
\hline
\end{tabular}




\begin{tabular}{lccc}
\hline Current controller & $k_{p}+\frac{k_{h} \cdot B_{h} \cdot s}{s^{2}+B_{h} \cdot s+\left(\omega_{h}^{2}\right)}=1.04+\frac{100 \cdot(2 \pi) \cdot s}{s^{2}+2 \pi \cdot s+(100 \pi)^{2}}$ & $1.28 \mathrm{kHz}$ & $58.6^{\circ}$ \\
Voltage controller & $k_{p}+\frac{k_{i}}{s}=2.5+\frac{0.04}{s}$ & $10 \mathrm{~Hz}$ & $87^{\circ}$ \\
& & \\
\hline
\end{tabular}

Apparently, the islanding detection algorithms could be also evaluated by simplifying the power inverter by eliminating the MPPT algorithms and the dc voltage regulation loop of the inverter (in that case, a constant DC-link voltage should be assumed). However, those algorithms can be affected by the islanding detection, and vice versa. Therefore, they have been taken into account in this study.

\section{Active Islanding Detection Methods}

These techniques intentionally introduce disturbances at the output of the inverter in order to determine whether they affect voltage, frequency or impedance parameters, in which case it is assumed that the grid is disconnected and the inverter must be isolated from the load.

Active techniques have the advantage of remarkably reducing or even eliminating the socalled Non-detection Zone (NDZ) [7], but in order to achieve their purpose they may deteriorate the quality of the grid voltage or even they may cause instability.

Active methods can be classified into: positive feedback based methods and harmonic injection based methods. In the following sections, these methods will be discussed.

\subsection{Active Methods Based on Positive Feedback}

Active methods based on positive feedback present the particularity to affect, in a controlled way, the voltage, the frequency and the remaining parameters associated with the inverter. In the case when there is a change that produces that the aforementioned variables are outside the assigned threshold and the grid is not connected, because of the positive feedback the system reaches levels of over/under voltage (OUV) or over/under frequency (OUF) [11], so that the islanding situation may be detected.

Some islanding detection techniques based on positive feedback are presented in the following.

\subsubsection{Variation of active power and reactive power}

This method [11] involves injection of active power and reactive power from the inverter to the grid system. In an islanding condition the power flow from the inverter to the load affects current and voltage in the PCC. The voltage variation with regard to the active power injected by the inverter to the load during an islanding condition is obtained starting from the active power generated by the DG in an islanding condition, following (1). R expresses the equivalent resistance of the load, $P_{D G}$ is the distributed generator power, $P_{L O A D}$ is the load power and $\mathrm{V}$ is the voltage in the Point of Common Coupling (PCC).

$P_{D G}=P_{L O A D}=\frac{V^{2}}{R}$

Differentiating $P_{D G}$ with regard to the voltage and expressing it in terms of power it results:

$\frac{d P_{D G}}{d V}=2 \cdot \frac{V}{R}=2 \cdot \sqrt{\frac{P_{D G}}{R}}$

Hence the voltage variation as a function of power can be expressed as: 
$\Delta V=\frac{\Delta P_{D G}}{2} \cdot \sqrt{\frac{R}{P_{D G}}}$

Since both $R$ and $P_{D G}$ are constant, voltage variation is directly proportional to the variation of active power. Hence, it is possible to vary the active power injected by the inverter in order to bring the amplitude of the voltage outside the normal operating range and be able to detect islanding.

It is necessary to choose carefully when the power is injected because continuous variations of the injected power can perturb the Maximum Power Point Tracking (MPPT) algorithms. For these reasons, this method involves the injection of active power only when the voltage measured at the PCC exceeds a certain threshold value (Vs).

The time needed by the algorithm to detect a fault can be adjusted with a $\mathrm{K}_{v}$ factor that increases o decreases $\mathrm{dP}$ proportionally to the voltage variation. This value should be chosen large enough to detect the islanding situation avoiding overcurrents which may damage the system elements. An initial value of $K_{v}$ can be obtained from Equation 2. The reference for the inverter current control loop can be calculated as follows:

$I_{\text {ref }}=\frac{d P+P_{D G}}{V}$

Where $d P=K_{v}(V-V n), V n$ and $V$ being the amplitude of the grid nominal voltage and the measured actual value, respectively.

Similarly to the relationship between voltage and active power, a strong dependence between frequency and reactive power exists, which may be used to develop another method of islanding, based on measuring the grid frequency. Since Std. 929-2000 recommends DG operation near unity power factor, the generated reactive power must be zero in normal operation. At the beginning of islanding, Equation 5 remains valid, so that the frequency depends on the values of the inductive and capacitive components of the load. Therefore, the variation of $Q$ with $\omega$ follows Equation 6 , where $\omega_{0}$ is the resonance frequency of the equivalent RLC circuit, Equation 7.

$$
\begin{aligned}
& Q_{D G}=Q_{L O A D}=0=V^{2} \cdot\left(\frac{1}{\omega \cdot L}-\omega \cdot C\right) \\
& \frac{Q-0}{\omega-\omega_{o}}=\left.\frac{d Q}{d \omega}\right|_{\omega=\omega_{O}} \\
& \omega_{o}=\frac{1}{\sqrt{L \cdot C}}
\end{aligned}
$$

Solving Equation 6, in order to determine the variation of the frequency as a function of $\Delta \mathrm{Q}$ and setting the frequency of the load at the resonance frequency, it is obtained:

$$
\Delta \omega=-V^{2} \cdot\left[\frac{\omega_{0}^{2} \cdot L}{\omega_{o}^{2} \cdot L \cdot C+1}\right] \cdot \Delta Q
$$

As observed from Equation 8, the frequency variation is directly proportional to the changes of reactive power. It can be obtained the expression of $\Delta f$ as a function of the quality factor, $Q_{\mathrm{f}}=R \cdot C \cdot \omega_{0}$, the resonance frequency, $f_{o}$, and the active power, $P_{D G}$, in an operation point, following Equation 9.

$$
\Delta f=-\frac{f_{o}}{2 \cdot P_{D G} \cdot Q_{f}} \Delta Q
$$


The reference frequency for the inverter control can be calculated as follows:

$f_{\text {ref }}=f_{g}+K_{f} \cdot\left(f-f_{g}\right)$

Where $f_{g}$ is the nominal grid frequency, $f$ is the measured frequency and $K_{f}$ is a factor that allows to accelerate the islanding detection. $K_{f}$ may be calculated following Equation 6 .

Figure 4 shows the whole block diagram of the method, where both active and reactive channels are disturbed.

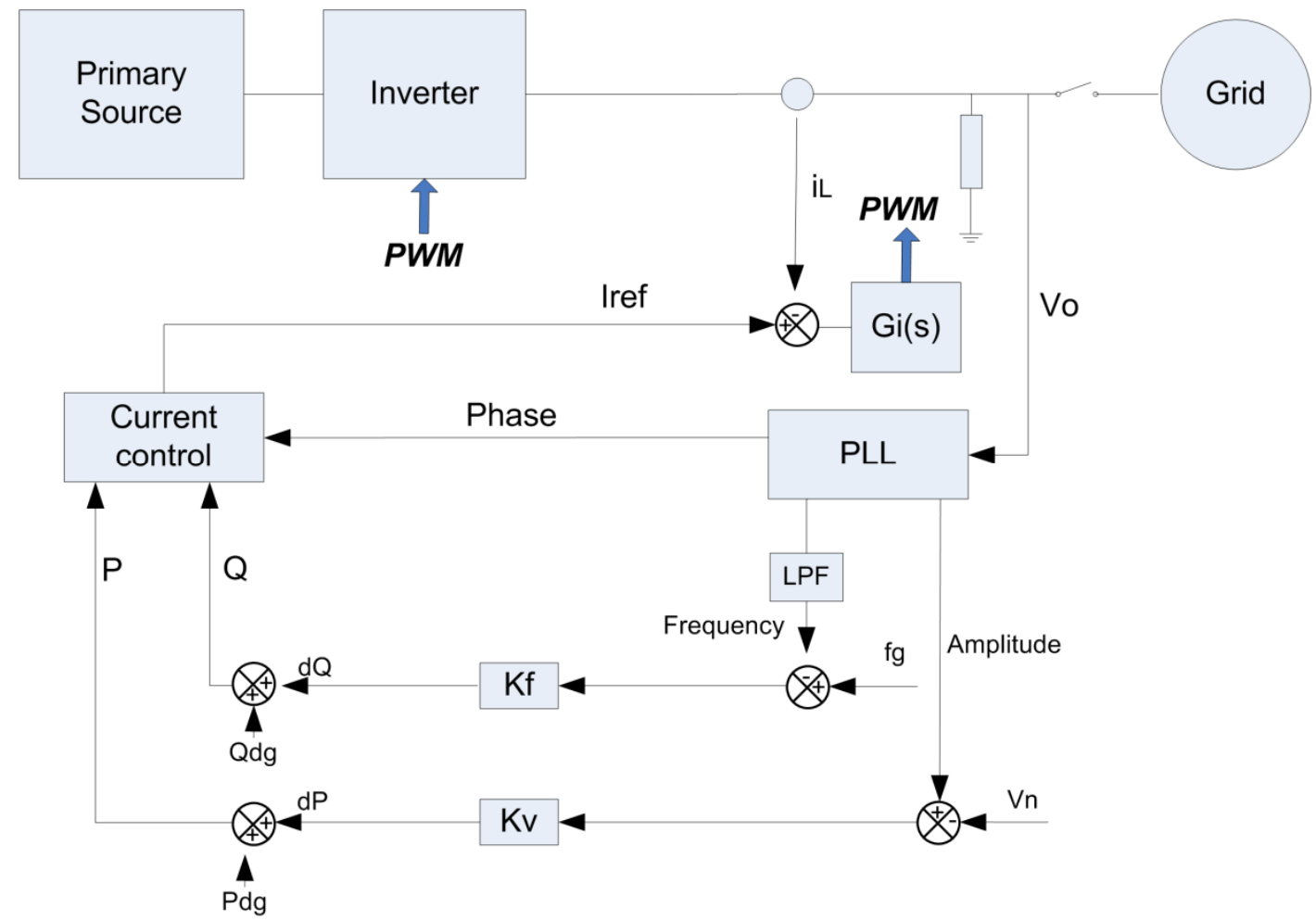

Fig. 4. Block diagram of $P$ and $Q$ injection method.

The disadvantage of this method is that it can generate false detections of islanding when several inverters are connected to the same point of the grid. Moreover, instability problems may appear because the inverter is continuously injecting disturbances into the grid.

\subsubsection{Sandia Voltage Shift and Sandia Frequency Shift}

This method [12-13] uses a positive feedback loop of the point of common coupling (PCC) voltage amplitude, being similar to the active power variation technique. If the voltage amplitude (usually it is measured its RMS value) decreases, the inverter reduces its output current and thus the output power. Taking into account Equations 1, 2 and 3 derived above, it is possible to express the active power variation in terms of the RMS voltage at the PCC and of its variation as:

$\Delta P_{D G}=2 \cdot \Delta V \cdot \frac{V}{R}$

The response time of the algorithm can be adjusted by a factor $K_{v}$ that increases or decreases the inverter current proportionally to the voltage variation. This value should be chosen following the same considerations that were described in the active power variation method. The reference for the inverter current control loop can be calculated as follows: 
$I_{\text {ref }}=\frac{d P+P_{D G}}{V}=\frac{K_{V} \cdot \Delta V+P_{D G}}{V}$

Sandia Frequency Shift (SFS) is based on the positive feedback of the frequency of the PCC voltage. When the grid is connected, the method detects and tries to amplify small changes in frequency, but the presence of the grid avoids it. When the grid is disconnected, the frequency changes produce a phase error. The positive feedback makes, in an iterative process, that this error pushes the fundamental frequency of the inverter beyond the thresholds of OUF. When the method is implemented, the reference frequency for the inverter is calculated as a function of both its value at the previous iteration $(n)$ and its variation $\Delta$ f. This is expressed as:

$f_{n+1}=f_{n}+K_{f} \cdot \Delta f$

Where $f_{n+1}$ is the reference frequency for the inverter in the $(n+1)$-th iteration cycle, $f_{n}$ is the frequency in the $n$-th cycle and $\mathrm{K}_{\mathrm{f}}$ is a constant that allows to accelerate the islanding detection. Finally $\Delta \mathrm{f}_{\mathrm{n}}$ is the frequency variation in each cycle. $\mathrm{K}_{\mathrm{f}}$ is designed to compensate the natural tendency of the system to move to the load resonance frequency when such a resonance frequency falls within the thresholds established to detect islanding.

In the $(n+1)$-th cycle the inverter injects a current with a certain frequency. Therefore, the load introduces a sliding phase angle $\varphi$ corresponding to an interval of time $T_{p s}$ following Equation 14.

$T_{p s}=\frac{\varphi}{2 \cdot \pi} T_{n+1}=\frac{\varphi}{2 \cdot \pi \cdot f_{n+1}}$

$\mathrm{K}_{\mathrm{f}}$ is chosen to maintain the sliding frequency below the resonance frequency. In principle, this condition implies that, for an increasing shift, the frequency in the $(n+1)$-th cycle must be greater than that one of the $n$-th cycle, which yields the following condition:

$f_{n+1}=\left(\frac{1}{f_{n}+K_{f} \cdot \Delta f_{n}}-\frac{\varphi}{2 \cdot \pi \cdot\left(f_{n}+K_{f} \cdot \Delta f_{n}\right)}\right)^{-1} \geq\left(\frac{1}{f_{n}}\right)^{-1} \rightarrow K_{f}>\frac{-\varphi \cdot f_{n}}{2 \cdot \pi \cdot \Delta f_{n}}$

Another issue for choosing the value of $K_{f}$ is the desired time response. This can be accomplished by imposing a minimum time variation called shift time, $\mathrm{T}_{\mathrm{f}}$. Therefore, it is obtained:

$f_{n+1}=\left(\frac{1}{f_{n}+K_{f} \cdot \Delta f_{n}}-\frac{\varphi}{2 \cdot \pi \cdot\left(f_{n}+K_{f} \cdot \Delta f_{n}\right)}\right)^{-1} \geq\left(\frac{1}{f_{n}}-T_{f}\right)^{-1}$

For frequencies close to the grid frequency, the term $2 \cdot \pi \cdot f_{n} \cdot T_{f}$ is appreciably greater that the phase-shift angle $\varphi$, whereas the term $\left(1-f_{n} \cdot T_{f}\right)$ is near one. With these simplifications it is obtained Equation 17.

$K_{f} \geq f_{n} \cdot \frac{|\varphi|+2 \cdot \pi \cdot f_{n} \cdot T_{f}}{\left(1-f_{n} \cdot T_{f}\right) \cdot 2 \cdot \pi \cdot \Delta f_{n}} \rightarrow K_{f} \geq \frac{f_{n}^{2} \cdot T_{f}}{\Delta f_{n}}$

These methods are easy to be implemented. They provide a good compromise between effectiveness of islanding detection, output power quality and reduced effects of the system transient response.

One of the main disadvantages of this method is that it slightly reduces the power quality at the inverter output. The other disadvantage of SVS and SFS is that these methods may have 
small impacts on the utility system transient response. However, these effects can be avoided by decreasing $\mathrm{K}_{\mathrm{v}}$ and $\mathrm{K}_{\mathrm{f}}$.

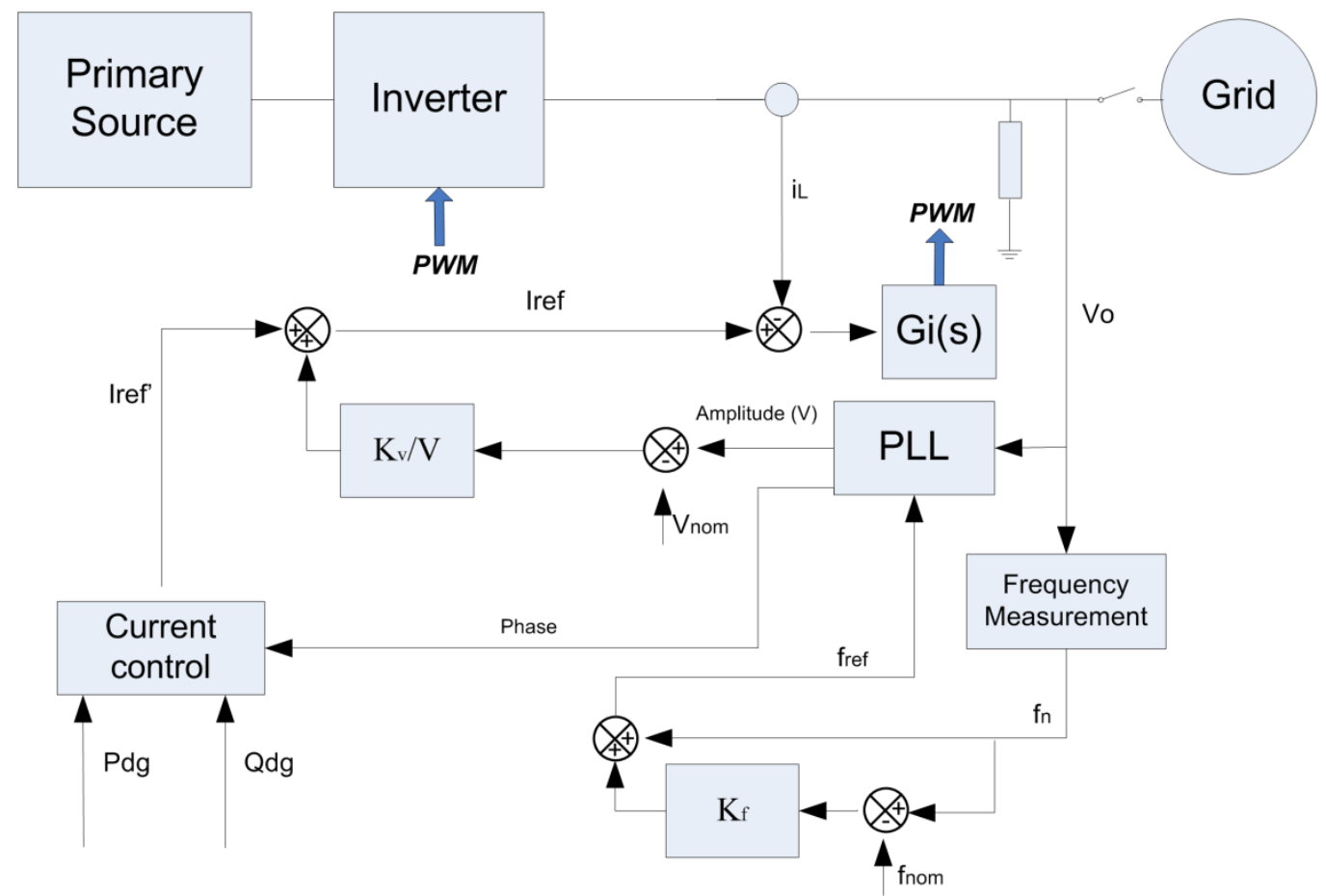

Fig. 5. Block diagram of the SVS and the SFS method.

\subsubsection{General Electric Frequency Schemes (GEFS)}

This method [16] injects a disturbance into the current that is generated by the inverter and evaluates the effects on the PCC. The disturbance is added to the control signals in a Synchronous Reference Frame (SRF), usually known as DQ frame. The active power is proportional to the $\mathrm{D}$ axis component and the reactive power is proportional to the $\mathrm{Q}$ axis component.

Because the microinverter is a single-phase system, the implementation in a DQ reference framework is not as obvious as in a three-phase system. However, single-phase quantities can be transformed in $D Q$ coordinates by the creation of a virtual $Q$ axis as shown in Figure 6. 


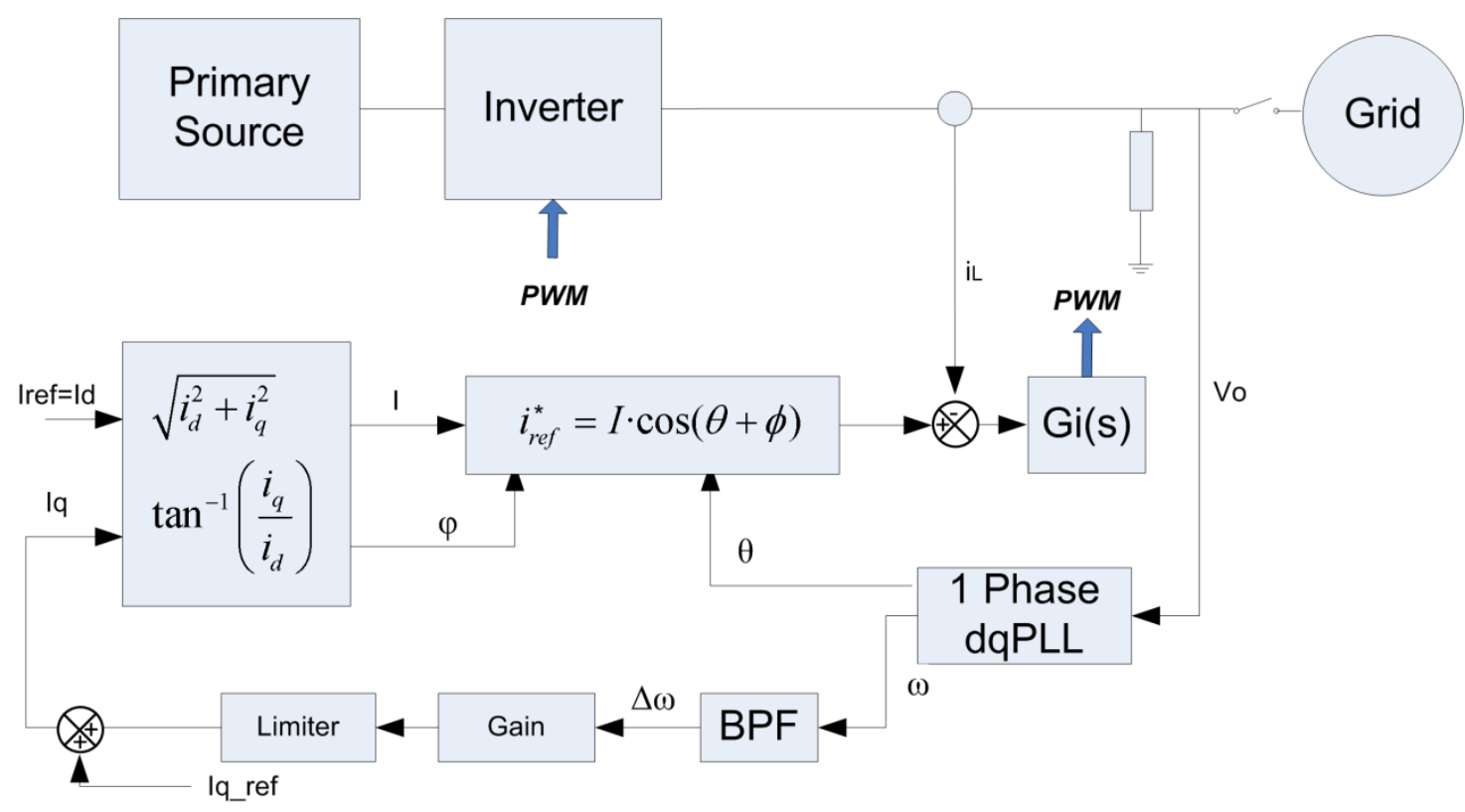

Fig. 6. Block diagram of the GEFS method applied to single-phase systems.

In the frequency diagram of General Electric, a bandpass filter (BPF) is used to obtain the variation of the $\mathrm{i}_{\mathrm{q}}$ component. This is done to cancel out the signal noise at low frequencies and the DC offset at high frequencies, caused by the positive feedback effect. The bandwidth of the filter must be chosen taking into account that standards suggest a time for islanding protection of approximately 2 seconds. Therefore, a bandwidth into the range $1 \mathrm{~Hz}-10 \mathrm{~Hz}$ is suitable to filter out the undesired components while respecting the response time suggested by the standards. When an islanding condition happens, the injected disturbance should be big enough to drive the system to instability, without significantly affecting the closed loop stability when the system is connected to the grid. The final element to consider is the limiter, which allows specifying the maximum injected current based on two premises: the maximum overcurrent capability of the inverter and the minimum power displacement factor that might be achieved. In this method, both the magnitude and the phase of the reference current are affected, as described by the following equations:

$$
\begin{aligned}
& \mathrm{I}=\sqrt{\mathrm{i}_{\mathrm{d}}^{2}+\mathrm{i}_{\mathrm{q}}^{2}} \text { and } \phi=\tan ^{-1}\left(\frac{\mathrm{i}_{\mathrm{q}}}{\mathrm{i}_{\mathrm{d}}}\right) \\
& \mathrm{i}_{\mathrm{ref}}^{*}=\mathrm{I} \cdot \cos (\theta+\phi)
\end{aligned}
$$

This method has the advantages of being easy to implement on a microcontroller, of a reduced NDZ, a low impact on power quality, and a high robustness against grid disturbances. Nevertheless, injection of the disturbance signals (frequency and voltage) should be as small as possible to preserve power quality.

\subsection{Active Methods Based on Harmonic Injection}

Active methods based on harmonic injection have the particularity of monitoring changes in grid impedance after the injection of a particular harmonic or a sub-harmonic [29-31]. They are based on the idea that when the grid is connected, its impedance is much lower than that of the load. Therefore, the injected harmonic flows into the grid. However, when the grid is disconnected, it flows through the load and produces a voltage distortion that can be detected. The method, as it has been implemented in [32], is explained in the following.

A second-order harmonic current is injected by acting on the angle calculated by the PLL for the inverter synchronization. This is achieved by injecting a sinusoidal signal synchronized 
cycle by cycle which forces to smoothly modify the angle of the inverter current. A feedback signal is extracted from the PCC voltage ( $V_{q}$ component) as a result of the injected harmonic signal.

Figure 7 shows a block diagram of this anti-islanding method.

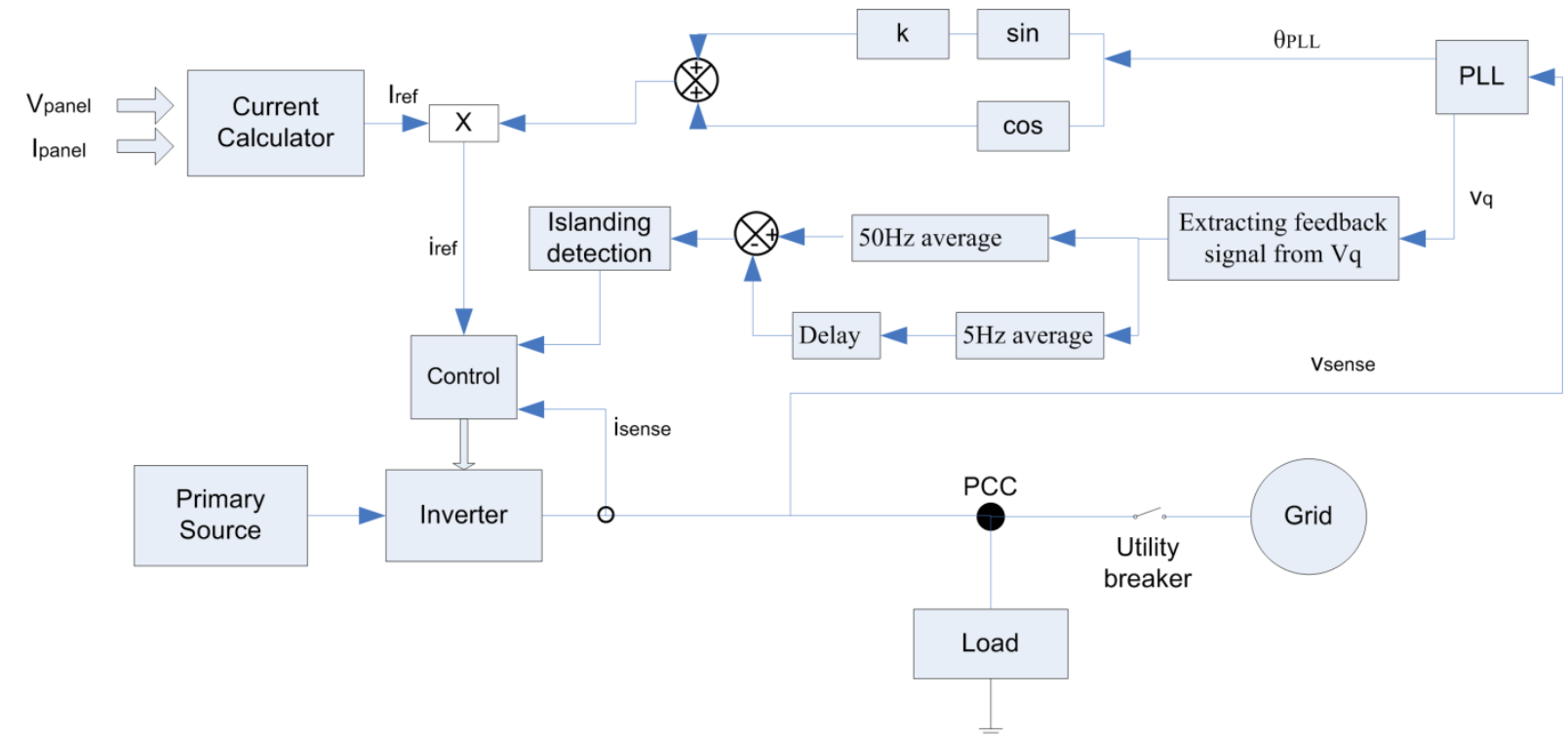

Fig. 7. Block diagram of harmonic injection method.

The injected harmonic signal, $\mathrm{S}_{\mathrm{inj}}$, is defined as:

$\mathrm{S}_{\mathrm{inj}}=\mathrm{k} \cdot \sin \left(2 \cdot \theta_{\mathrm{PLL}}\right)$

Where $\mathrm{k}$ is the gain used to choose the amount of disturbance necessary for the islanding detection, and $\theta_{\mathrm{PLL}}$ is the angle calculated by the PLL. As it can be observed in Equation 20, a second harmonic has been entered which will be added to the PLL phase and then scaled by the magnitude of the reference current of the system, as shown by Equation 21.

$\mathrm{i}_{\mathrm{ref}}=\mathrm{I}_{\mathrm{ref}} \cdot\left[\cos \left(\theta_{\mathrm{PLL}}\right)+\mathrm{k} \cdot \sin \left(2 \cdot \theta_{\mathrm{PLL}}\right)\right]$

The value of $k$ should be chosen taking into account three premises. The first one is that $k$ has to be big enough to detect an islanding condition. The second issue is that its value shouldn't be so great to produce an increase in the current THD exceeding the limits set by the standards. The third premise is that it should not affect in a significant way the amplitude of the reference current. In Equation 21 it can be observed that the perturbation can be treated in terms of a percentage of the reference current. In this case it was used a perturbation with an amplitude of $1 \%(\mathrm{k}=0.01)$, which meets the above conditions.

When the inverter is connected to the grid, the consequence of adding $k \cdot \sin \left(2 \cdot \theta_{\mathrm{PLL}}\right)$ is observed as a feedback signal in the voltage at the PCC. The feedback signal has the double of the fundamental frequency and its amplitude is related to the grid impedance value. This feedback signal can be extracted from the voltage at PCC after the Park Transformation (from $v_{\mathrm{q}}$ ). After the transformation, the feedback signal frequency will become half of the frequency, as shown below:

$\mathrm{v}_{\mathrm{q}}=-\sin (\theta) \cdot \mathrm{v}_{\alpha}+\cos (\theta) \cdot \mathrm{v}_{\beta}$

Considering a system of orthogonal voltages of the feedback voltage $\left(v_{\alpha} y v_{\beta}\right)$ due to the injected signal and considering $\alpha$ and $\beta$ voltages, they can be represented as: 
$\mathrm{v}_{\alpha}=\cos (2 \cdot \theta)$ and $\mathrm{v}_{\beta}=\cos \left(2 \cdot \theta-\frac{\pi}{2}\right)=\sin (2 \cdot \theta)$

Replacing the values of Equation 23 in Equation 24 and solving, it is obtained:

$\mathrm{v}_{\mathrm{q}}=-\sin (\theta) \cdot \cos (2 \cdot \theta)+\cos (\theta) \cdot \sin (2 \cdot \theta)$

$\mathrm{v}_{\mathrm{q}}=\sin (\theta)$

The feedback voltage signal can be calculated after Park Transformation through a second order band pass filter tuned at the fundamental frequency. After this, the peaks in absolute value are detected from signal $\mathrm{v}_{\mathrm{q}}$ and it is calculated the average value in $50 \mathrm{~Hz}$ and $5 \mathrm{~Hz}$. Finally, the difference between the two averaged values is taken to determine whether it is inside or outside a certain threshold value. If it is outside the threshold value, it is activated a delay to establish if the conditions persists, and in case it happens, islanding condition is activated.

The main advantages of this method are: it does not affect the zero crossings of the current waveform, the disturbance amplitude is so small that it can be injected without significantly affecting the current THD, and it presents a very low NDZ. The method drawbacks are: it slightly degrades the quality of the injected power by having a constant disturbance, and it can have trouble detecting false islanding during certain grid disturbances whose effects might match those of the injected harmonic.

\section{Simulation Results}

This section presents an accurate simulation study of the different methods described above. These simulations were carried out by means of PSIM ${ }^{\mathrm{TM}}$ software [33] and tested on the microinverter that was presented in section II, following the requirements of IEEE Std. 9292000 (type of load and quality factor). In all cases it was used an RLC load with a quality factor of 2.5. The values of the $R L C$ load are: $R=120 \Omega, L=153 \mathrm{mH}$ and $C=67 \mu F$.

The microinverter system has been simulated at an MPP of the PV array of $V_{p v}=29.25 \mathrm{~V}$, $I_{p v}=14.7 A\left(P_{p v}=430 \mathrm{~W}\right)$. The refreshing frequency of the MPPT algorithm is much lower that than of the current and voltages loops. All the control loops of the push-pull DC-DC converter and of the inverter are operating when the islanding situation occurs at $t=0.5 \mathrm{~s}$. The simulation results show the response of the most important magnitudes of the microinverter during the islanding detection.

Figure 8.a. shows the results of the islanding detection method based on the variation of active power through the use of voltage feedback. The value of $\mathrm{K}_{\mathrm{v}}=15$ determines the trip time. In this graph it is possible to observe how the microinverter disconnection is produced in $245 \mathrm{~ms}$, complying with the time set by the standards (Maximum trip time $=120$ cycles) [25]. 

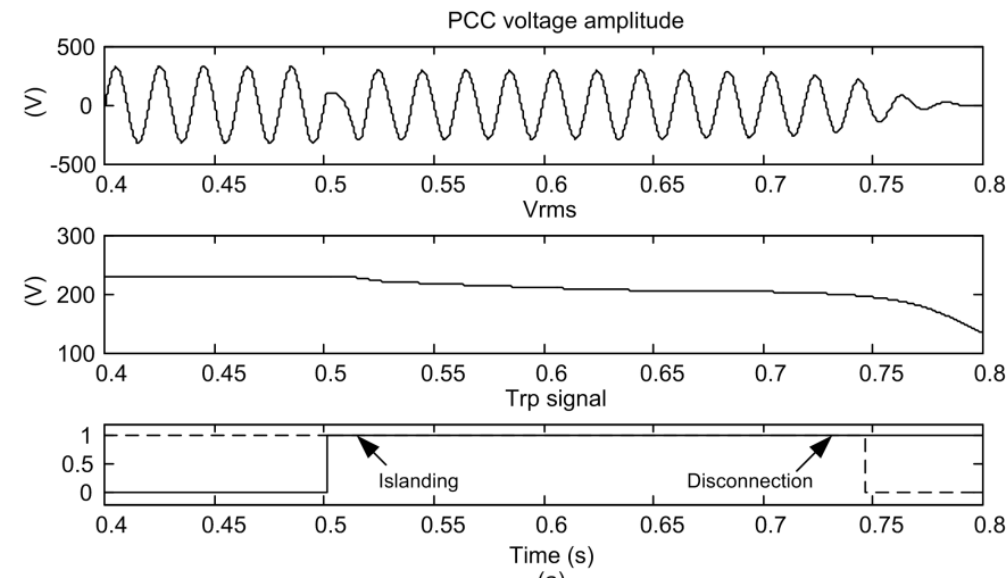

(a)

Fig. 8.a. PCC voltage (up), RMS Voltage (middle) and islanding detection (down), with Active power injection.

Figure 8.b. shows the transient response of the most important electrical variables of both the DC-DC converter and of the inverter:

$-I_{p v} \equiv$ Current supplied by the PV array

$-\mathrm{V}_{\mathrm{g}} \equiv$ Voltage at the PV array

$-I_{L x} \equiv$ Current through the output inductor of the push-pull converter

- $\mathrm{V}_{\mathrm{DC}} \equiv$ Inverter DC-link voltage

- $I_{\text {inv }} \equiv$ Inverter output current supplied to the PCC
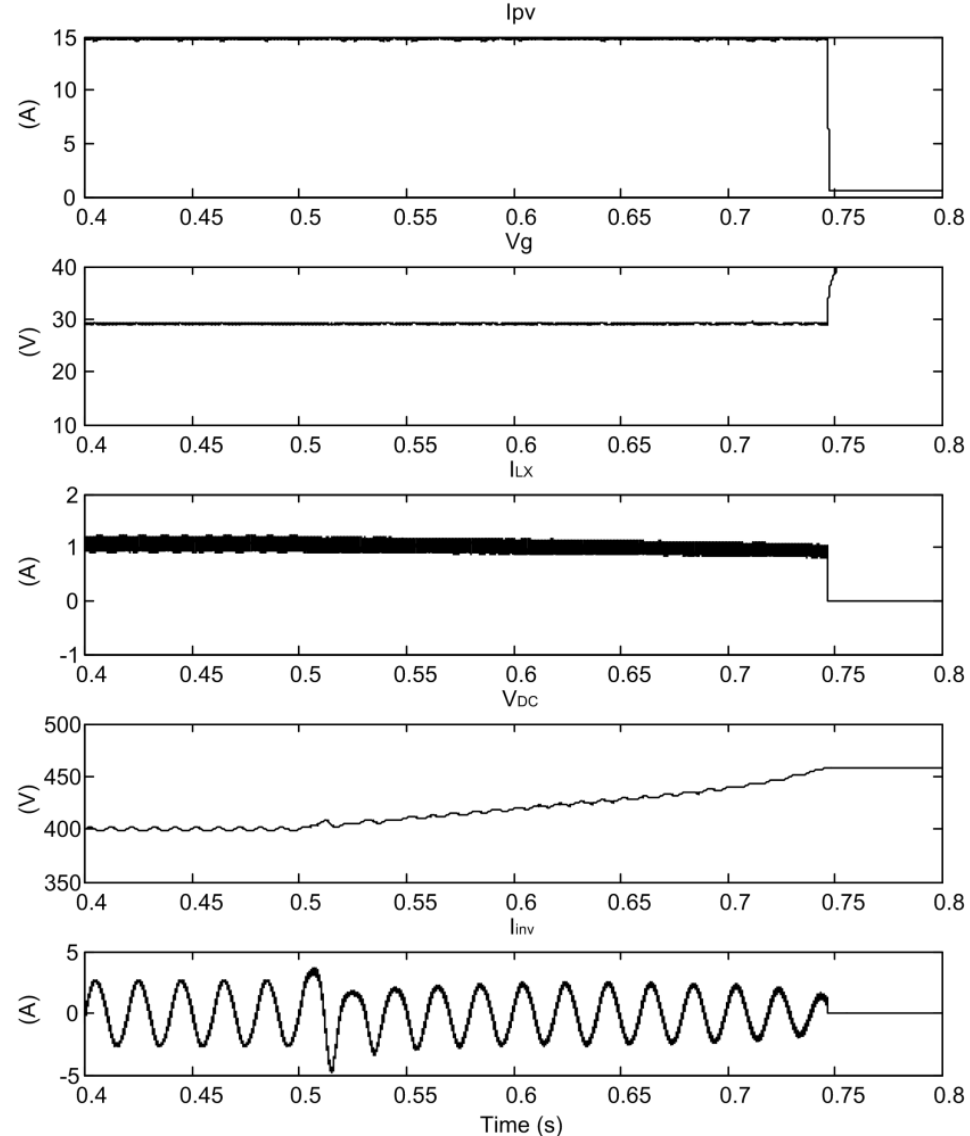

(b)

Fig. 8.b.Transient response of the most important electrical variables of both the DC-DC converter and of the inverter, presented when the active power injection method is operating. 
It is observed from Fig. 8.b. that the islanding detection based on variation of the active power produces transient voltages and currents in the power converters that are not dangerous for the power semiconductors and filtering components. The distortion of the current injected by the inverter to the $P C C, T H D_{i}$, is less than $3.33 \%$ at full power.

Figure 9, corresponding to the islanding detection method based on variation of reactive power through the use of frequency feedback, is analogous to Fig. 8. The value of $K_{f}=4$ determines the trip time. It is observed from Fig. 9.a. that the trip time is $230 \mathrm{~ms}$, well inside the maximum time defined by standards.
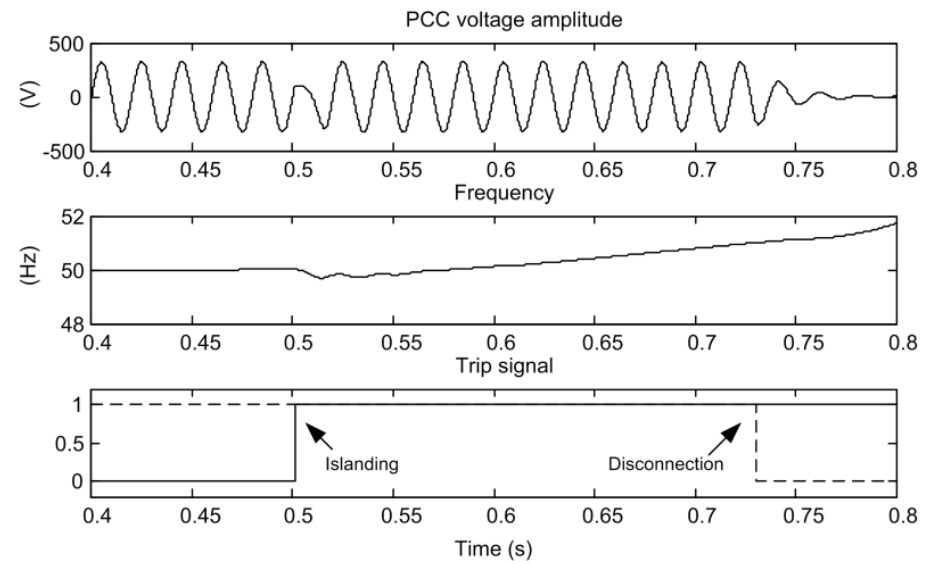

Fig. 9.a. PCC voltage (up), frequency (middle) and islanding detection (down), with Reactive power injection.
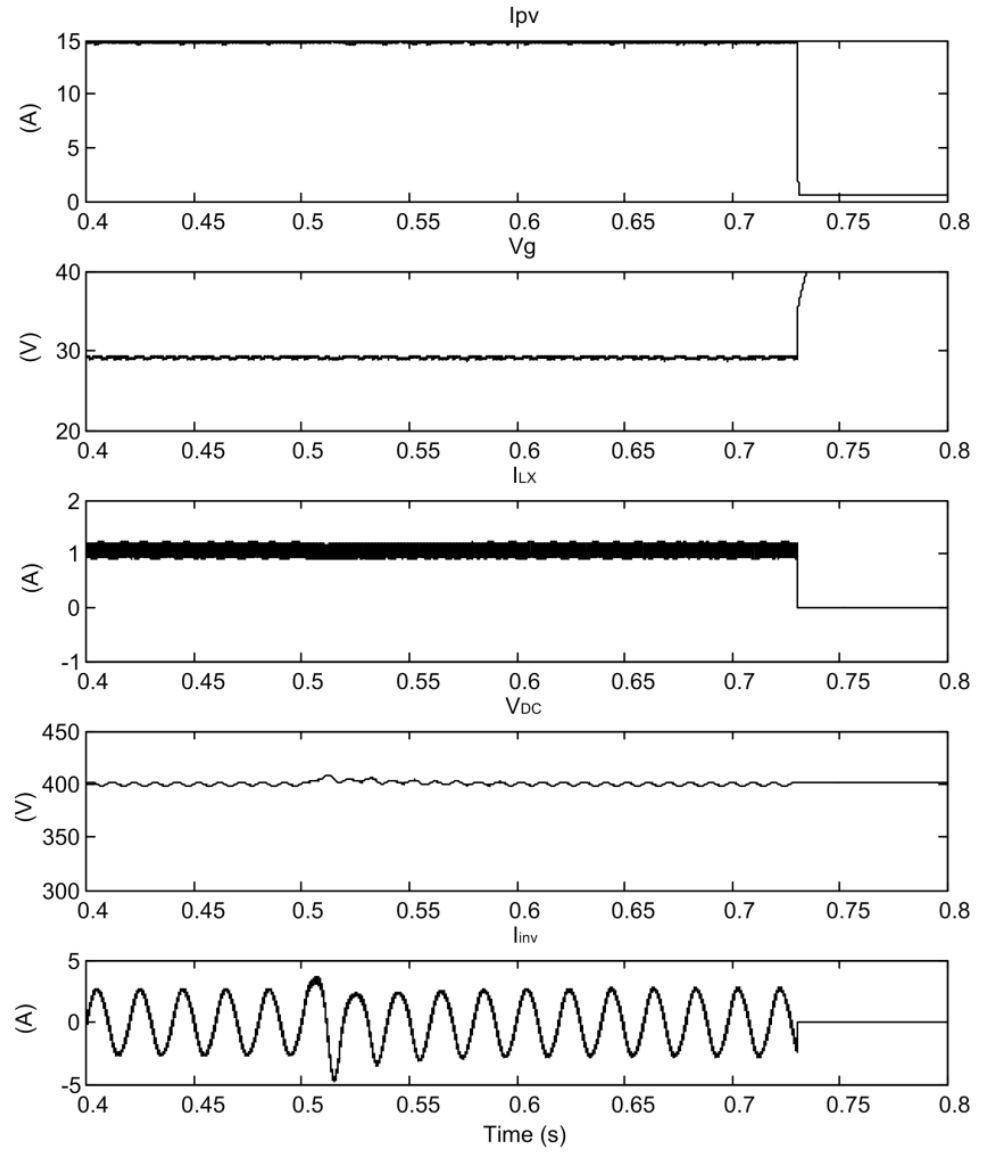

(b) 
Fig. 9.b.Transient response of the most important electrical variables of both the DC-DC converter and of the inverter, presented when the reactive power injection method is operating.

It is observed from Fig. 9.b. that the transients during islanding detection are acceptable for the power stage. The distortion of the current injected by the inverter to the $P C C, T H D_{i}$, is less than $3.33 \%$ at full power, and the reactive power is less than 0.68VAR when the islanding situation is presented.

Figures 10.a., 10.b., 11.a. and 11.b shows the results of the SVS and SFS methods, which have similar characteristics to those presented in the variation of active and reactive power methods.
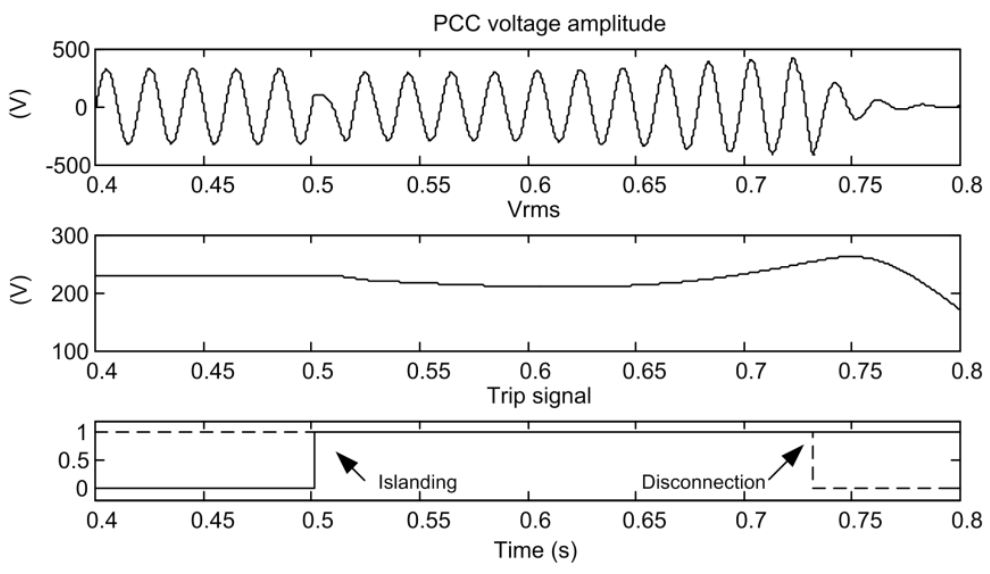

(a)

Fig. 10.a. PCC voltage (up), frequency (middle) and islanding detection (down), with SVS method.
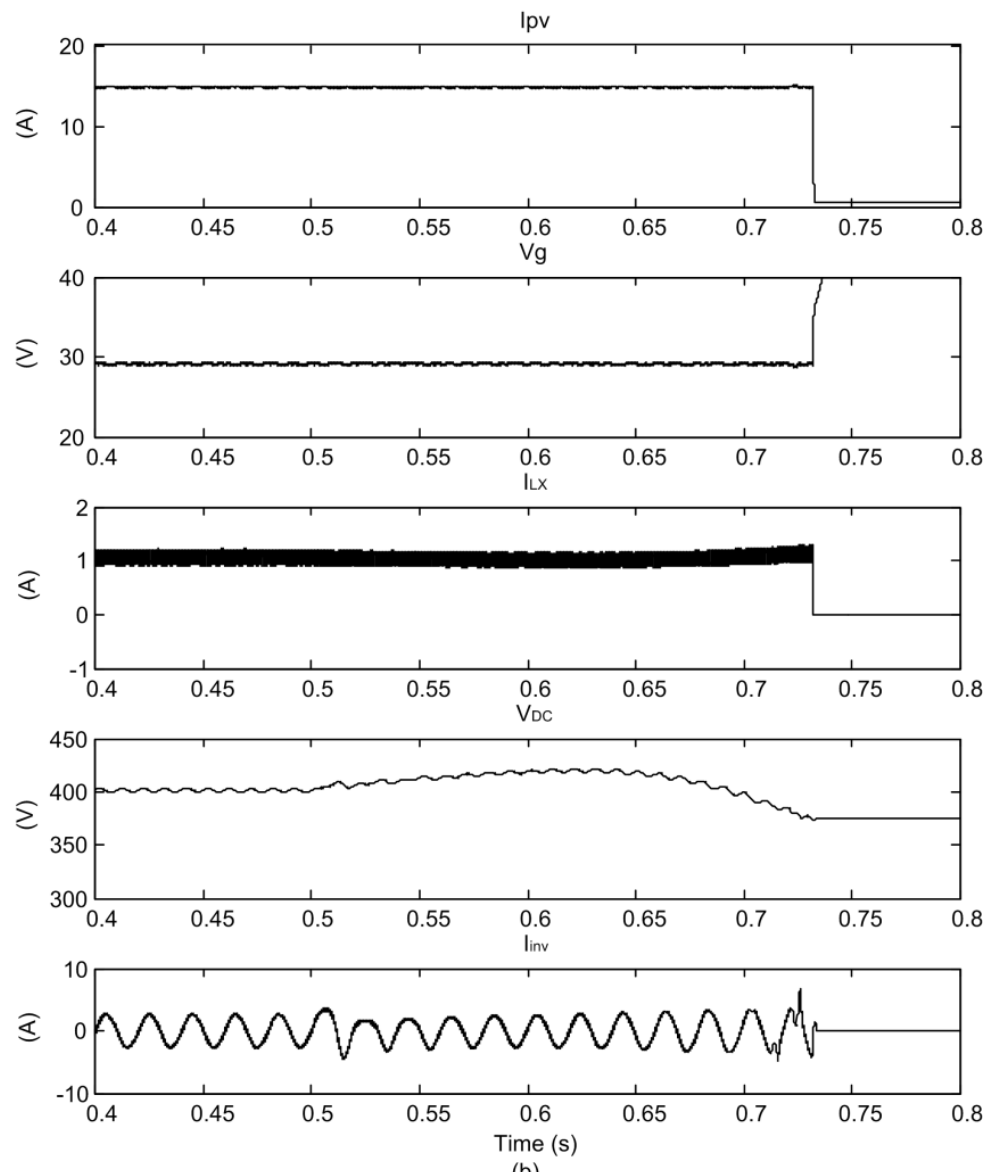

(b) 
Fig. 10.b. Transient response of the most important electrical variables of both the DC-DC converter and of the inverter, presented when the SVS method is operating.
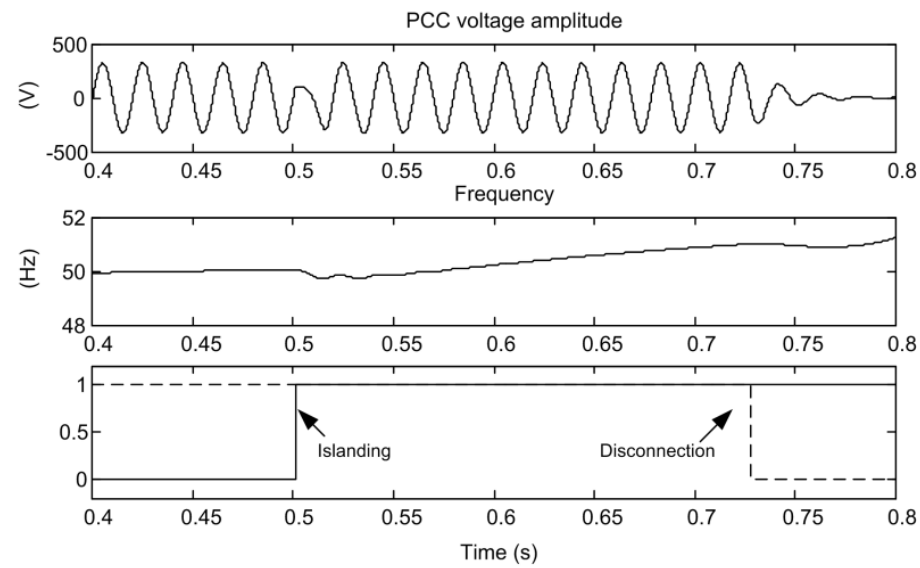

(a)

Fig. 11.a. PCC voltage (up), frequency (middle) and islanding detection (down), with SFS method.
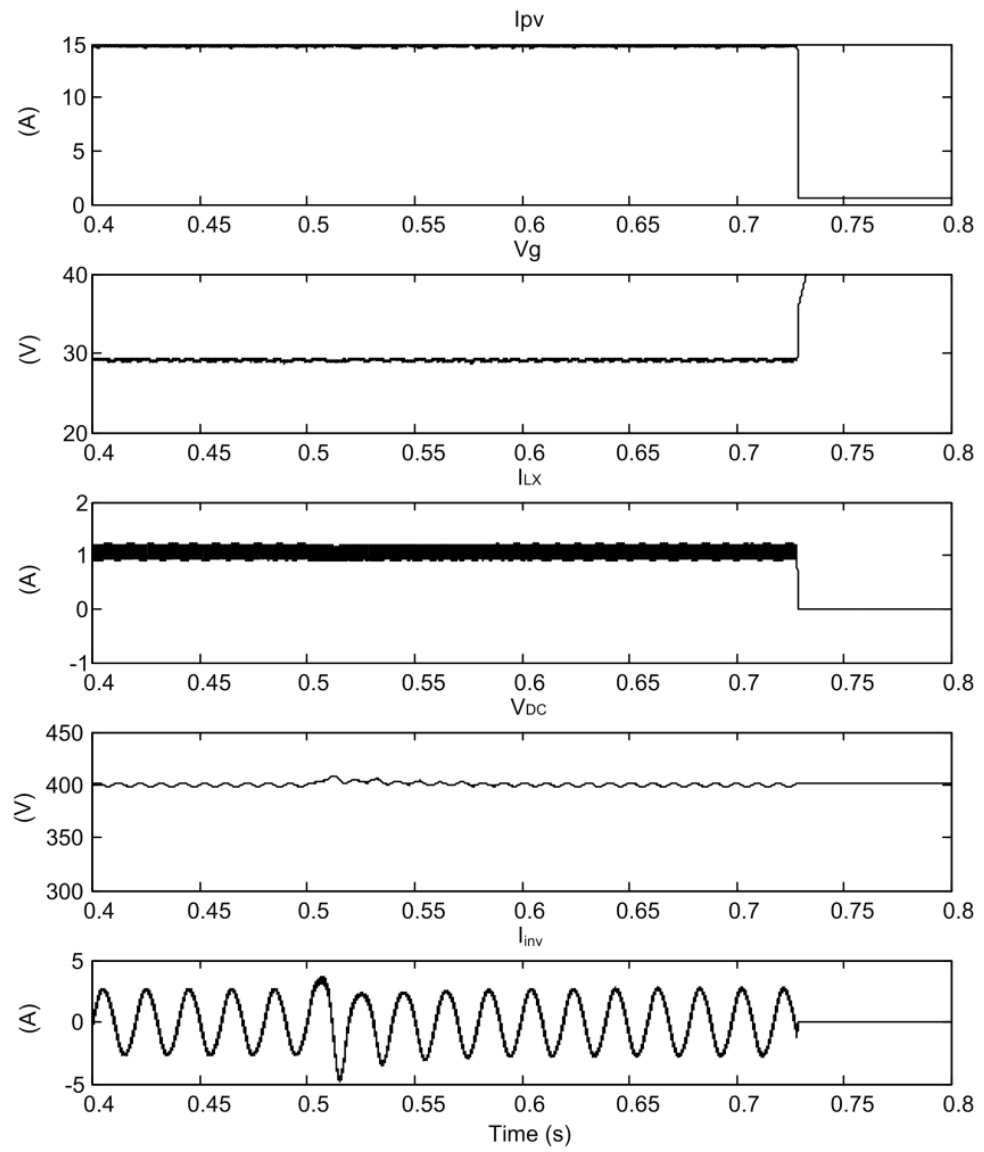

(b)

Fig. 11.b. Transient response of the most important electrical variables of both the DC-DC converter and of the inverter, presented when the SFS method is operating.

The values of the $T H D_{i}$, reactive power and trip signal for both, SVS method and SFS method are presented in the Table 3.

The power injection method and the SVS method have the problem that the DC_LINK voltage level can be have values high and dangerous for the components of the microinverter, this level is dependents of the size the disturbance injected. 
Figure 12 shows the results of the GEFS method. It can be seen that when islanding appears there is a variation in the $\mathrm{I}_{\mathrm{q}}$ component that makes the reference current to vary in both magnitude and angle so that a feedback effect happens. This effect pushes the microinverter frequency (or voltage) outside the established limits.
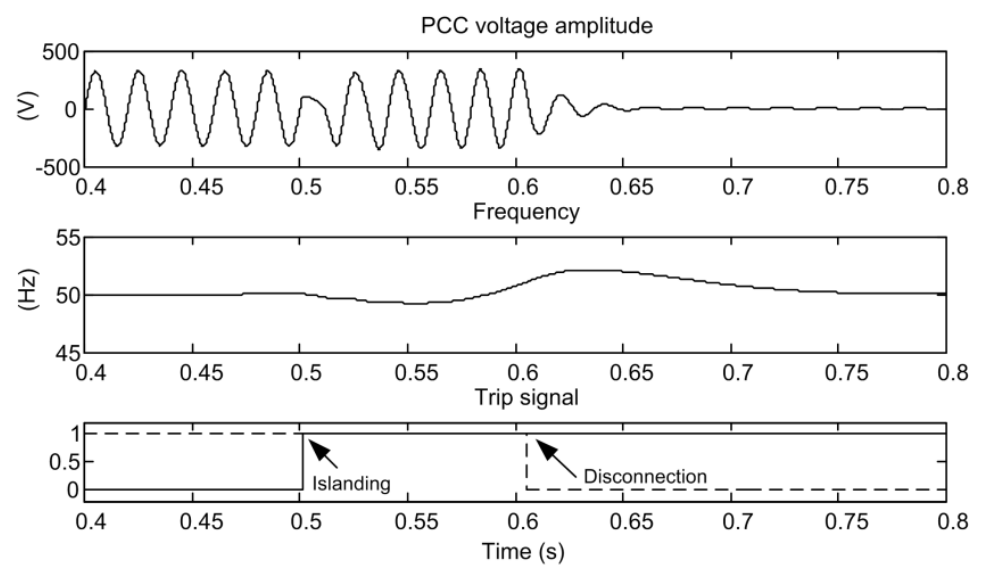

(a)

Fig. 12.a. PCC voltage (up), frequency (middle) and islanding detection (down), with GEFS method.
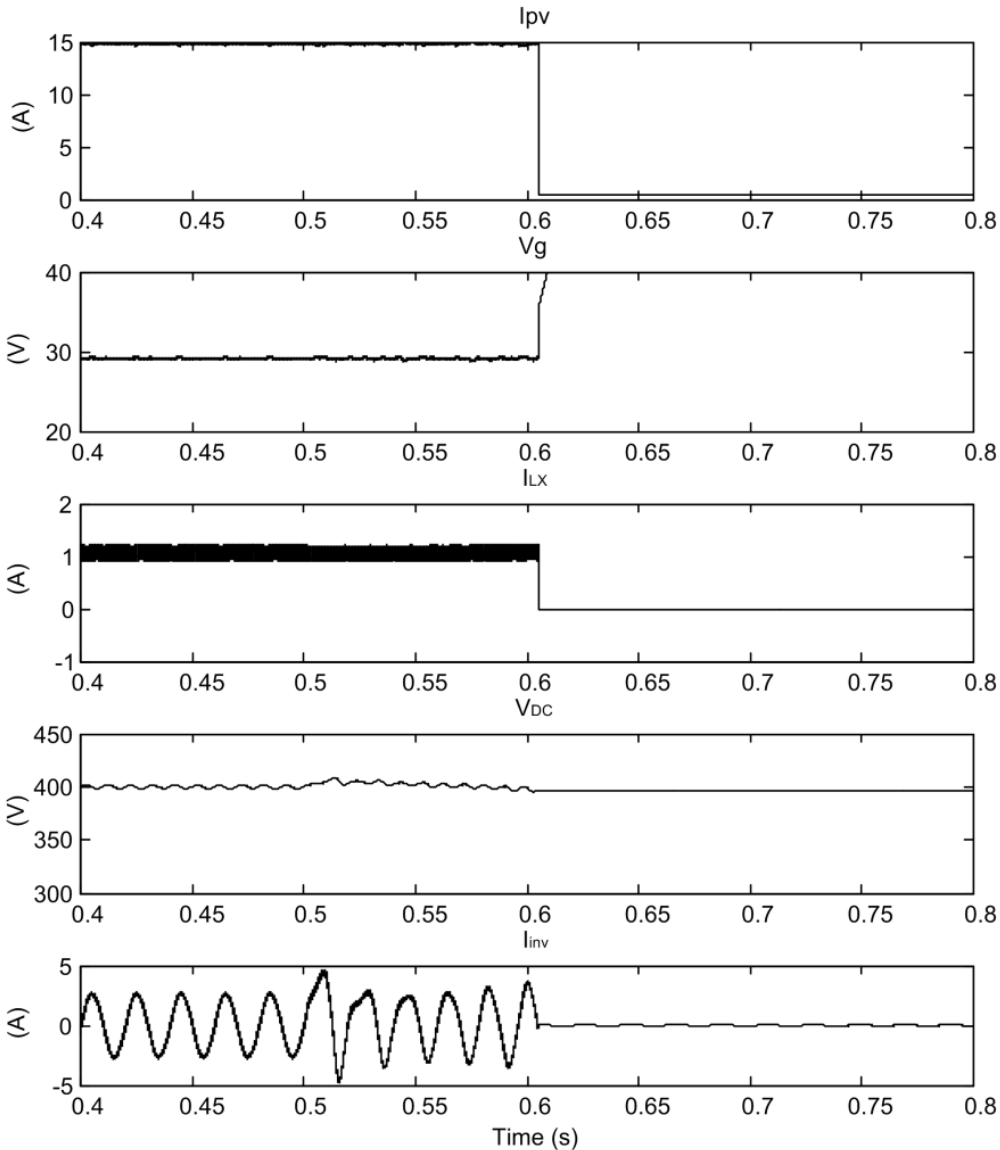

(b)

Fig. 12.b. Transient response of the most important electrical variables of both the DC-DC converter and of the inverter, presented when the GEFS method is operating.

It is observed from Fig. 12.b. that the transients during islanding detection are acceptable for the power stage. The distortion of the current injected by the inverter to the PCC, $T H D_{i}$, is 
less than $3.3 \%$ at full power, and the reactive power is less than 3.75VAR when the islanding situation is presented.

Figure 13 shows the results achieved by the impedance detection method. Note that when islanding situation occurs, the component $\mathrm{v}_{\mathrm{q}}$ changes as a result of the impedance variation at the frequency of the injected harmonic, so that the islanding condition may be detected.
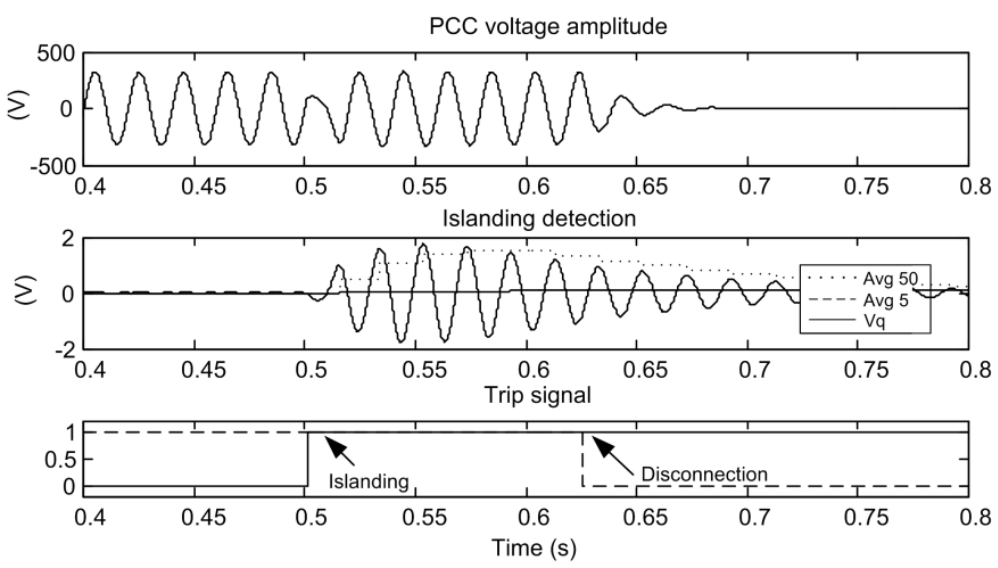

(a)

Fig. 13.a. PCC voltage and islanding detection, with impedance detection method.
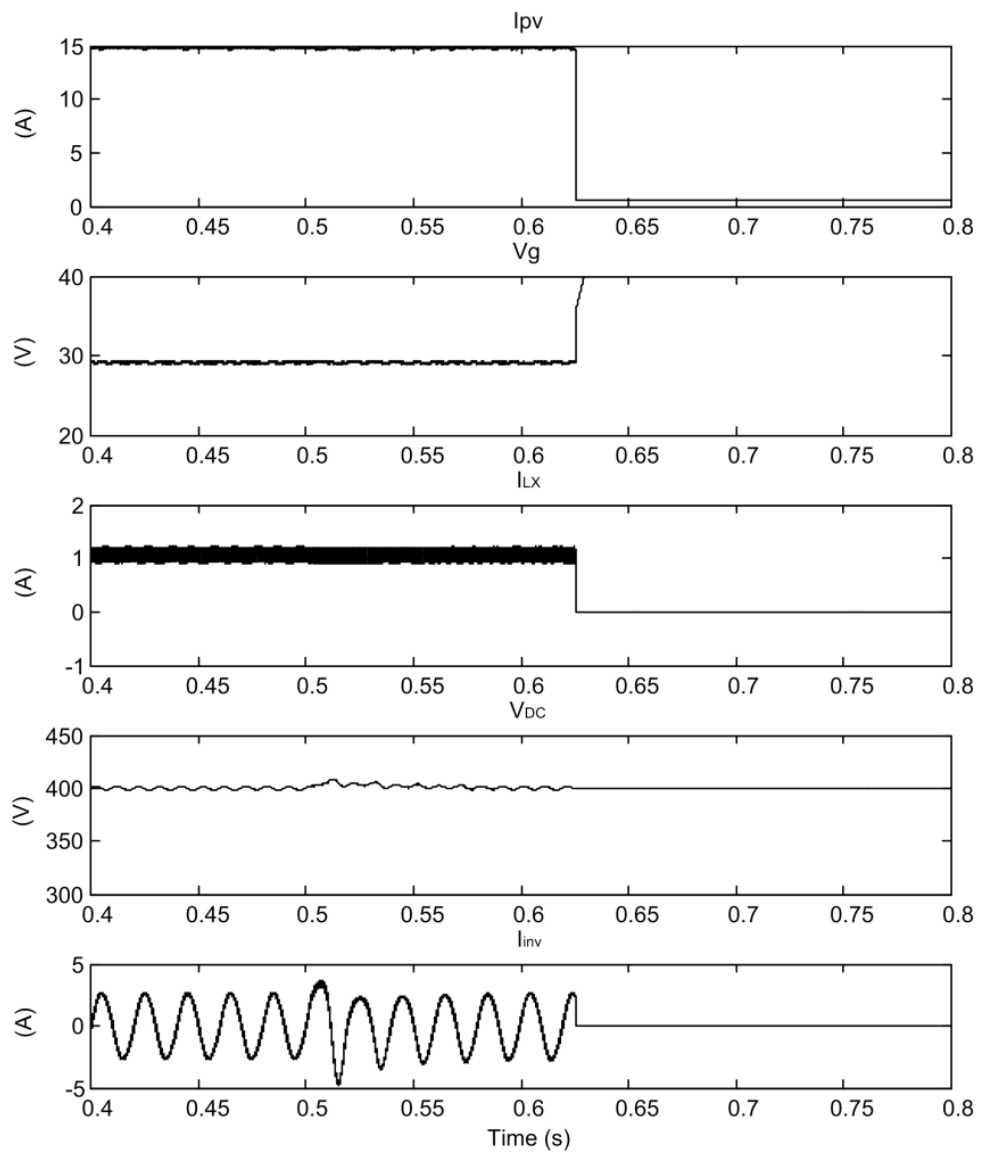

(b)

Fig. 13.b. Transient response of the most important electrical variables of both the DC-DC converter and of the inverter, presented when the impedance detection method is operating.

It is observed from Fig. 13.b. that the transients during islanding detection are acceptable for the power stage. The distortion of the current injected by the inverter to the $P C C, T H D_{i}$, is 
less than $3.37 \%$ at full power, and the reactive power is less than 1.30VAR when the islanding situation is presented.

It is worth to point out that, for all the methods previously analyzed, the $T H D_{i}$ never exceeds $3.5 \%$ at nominal power. The method that has most effect about the reactive power is the GEFS methods however the amount reactive power produced during the islanding condition only was $0.87 \%$ of the active power.

Moreover the methods based in harmonic injection (GEFS method and impedance detection method) have the trip time most short in comparison with the methods based on feedback positive. Additionally these methods present a good transitory response similar to reactive power variation method and SFS method.

Table 3 provides information to compare the trip time, $\mathrm{THD}_{\mathrm{i}}$ and reactive power of the different methods.

Table 3. Comparison of the Different Active Methods for Islanding Detection

\begin{tabular}{llcc}
\hline \multicolumn{1}{c}{ Method } & \multicolumn{1}{c}{ Trip time } & $\mathrm{THD}_{\mathrm{i}}$ & Reactive Power \\
\hline Active power variation & $0.245 \mathrm{~s}$ with $\mathrm{Kv}=15$ & $3.33 \%$ & $1.37 \mathrm{VAR}$ \\
Reactive power variation & $0.230 \mathrm{~s}$ with $\mathrm{K}_{\mathrm{f}}=4$ & $3.30 \%$ & $0.68 \mathrm{VAR}$ \\
$\mathrm{SVS}$ & $0.231 \mathrm{~s}$ with $\mathrm{Kv}=5.5$ & $3.40 \%$ & $1.64 \mathrm{VAR}$ \\
$\mathrm{SFS}$ & $0.228 \mathrm{~s}$ with $\mathrm{K}_{\mathrm{f}}=3.5$ & $3.50 \%$ & $0.82 \mathrm{VAR}$ \\
GEFS & $\begin{array}{l}0.1 \text { to } 0.2 \mathrm{~s} \text { as a function of } \\
\text { the size of the disturbance }\end{array}$ & $3.30 \%$ & $3.75 \mathrm{VAR}$ \\
Impedance detection & $\begin{array}{l}0.1 \text { to } 0.2 \mathrm{~s} \text { as a function of } \\
\text { the size of the disturbance }\end{array}$ & $3.37 \%$ & $1.30 \mathrm{VAR}$ \\
& &
\end{tabular}

\section{Conclusion}

In this paper an analysis of several active inverter-resident methods for islanding detection in single phase photovoltaic microinverters was presented. An important novelty of this study is that no simplifications of the power stages (DC-DC converter + inverter) control structures have been performed. The simulation results have been obtained with the MPPT algorithm, the control loops of the DC-DC converter and all the control loops of the inverter under operation. Therefore, the effect of the islanding detection methods on the transient response of the electrical magnitudes of the power stages can be evaluated.

For the same test conditions as established by the IEEE 929 all methods meet the detection time. However, positive feedback based methods have a longer trip time than those based on harmonic injection. The reason for that is that positive feedback methods need a considerable amount of time to reach the UOV or UOF, whereas the methods based on harmonic injection detect variations in the impedance of the grid, which allows working with smaller detection thresholds.

It has been observed that no detection method produces dangerous transient overvoltages or overcurrents in the power converters and in their filtering components.

Although all the methods under study are based on disturbing the grid, potentially degrading power quality, if the design parameters are carefully chosen, their effects on power quality are not significant.

\section{Acknowledgements}

This work was supported by the Spanish Ministry of Science and Innovation under Grant ENE2009-13998-C02-02.

\section{References}


[1] Y. Ruan, Q. Liu, W. Zhou, R. Firestone, W. Gao, T. Watanabe, Optimal option of distributed generation technologies for various commercial buildings, Applied Energy 2009; 86: 1641-1653.

[2] P. Mancarella, G. Chicco, Global and local emission impact assessment of distributed cogeneration systems with partial-loads models, Applied Energy 2009; 86: 2096-2106.

[3] G.C. Bakos, Distributed porwer generation: A case study of small scale PV power plant in Greece, Applied Energy 2009; 86: 1757-1766.

[4] R.W. Erickson, A.P. Rogers, A Microinverter for Building-Integrated Photovoltaics, Applied Power Electronics Conference and Exposition, 2009. APEC 2009. Twenty-Fourth Annual IEEE, pp.911917, 15-19 Feb. 2009

[5] M. Calais, J. Myrzik, T. Spooner, V.G. Agelidis, "Inverters for single-phase grid connected photovoltaic systems-an overview, Power Electronics Specialists Conference, 2002. pesc 02. 2002 IEEE 33rd Annual, vol.4, pp. 1995- 2000, 2002.

[6] F. Kang, S. Park, J. Kim, Photovoltaic power interface circuit incorporated with a buck-boost converter and a full-bridge inverter, Applied Energy 2005; 82: 266-283.

[7] V. Task, Evaluation of islanding detection methods for photovoltaic utility-interactive power systems, Tech. Rep. IEAPVPS T5-09:2002, March. 2002.

[8] P. Mahat, C. Zhe, B. Bak-Jensen, Review of islanding detection methods for distributed generation, in Third International Conference on Electric Utility Deregulation and Restructuring and Power Technologies, 2008, pp.2743-2748.

[9] M. Francesco De, L. Marco, and D. A. Antonio, Overview of Anti-Islanding Algorithms for PV Systems. Part II: Active Methods, Proc. of EPE-PEMC, 2006, pp. 1884-1889.

[10] I.J. Balaguer, K. Heung-Geun, F.Z. Peng, E.I. Ortiz, Survey of photovoltaic power systems islanding detection methods, Industrial Electronics, 2008. IECON 2008. 34th Annual Conference of IEEE, pp.2247-2252, m10-13 Nov. 2008.

[11] M. Francesco De, L. Marco, D. A. Antonio, P. Alberto, Overview of Anti-Islanding Algorithms for PV Systems. Part I: Passive Methods, Proc. of EPE-PEMC, 2006, pp. 1878-1883.

[12] J. Stevens, R. Bonn, J. Ginn, S. Gonzalez, G. Kern, Development and testing of an approach to anti-islanding in utility interconnected photovoltaic systems, Sandia Report SAND 2000-1939, Aug., 2000. Available: http://photovoltaics.sandia.gov/docs/PDF/0800steve.pdf.

[13] P. Sanchis, L. Marroyo, J. Coloma, Design methodology for the frequency shift method of islanding prevention and analysis of its detection capability, Progress in Photovoltaics: Research and Applications, Vol. 13, No. 5, pp. 409-428, 2005. Available: http://dx.doi.org/10.1002/pip.613

[14] L.A.C. Lopes, H. Sun, Performance assessment of active frequency drifting islanding detection methods, IEEE Trans. On Energy Conversion, Vol. 21, No. 1, March 2006, p. 171-180.

[15] M. E. Ropp, M. Begovic, A. Rohatgi, Analysis and performance assessment of the active frequency drift method of islanding prevention, IEEE Transactions on Energy Conversion, Vol. 14, No. 3, pp. 810-816, September 1999.

[16] Z. Ye, R. Walling, L. Garces, R. Zhou, L. Li, T. Wang, Study and Development of Anti-lslanding Control for Grid-Connected Inverters, General Electric Global Research Center, Niskayuna, New York, USA, 2004. Available: http://www.nrel.gov/docs/fy04osti/36243.pdf

[17] N. Mohan, T. Undeland, W. Robbins, Power electronics: converters, applications, and design, John Wiley \& Sons, 1995.

[18] M. Liserre, F. Blaabjerg, R. Teodorescu, Z. Chen, Power converters and control of renewable energy systems, ICPE 2004, Busan, Korea, Invited paper.

[19] J. Liang, T.C. Green, G. Weiss, Q. Zhong, Hybrid control of multiple inverters in an island-mode distribution system, PESC '03. IEEE 34th annual conference on power electronics specialist, 2003, vol. 1, pp.61-66, June 2003.

[20] T. Esram, P.L. Chapman, Comparison of Photovoltaic Array Maximum Power Point Tracking Techniques, Energy Conversion, IEEE Transactions on , vol.22, no.2, pp.439-449, June 2007.

[21] I.S. Kim, Sliding mode controller for the single-phase grid-connected photovoltaic system, Applied Energy 2006; 83: 1101-1115.

[22] L.G. Gonzalez, E. Figueres, G. Garcerá, O. Carranza, Maximum-power-point tracking with reduced mechanical stress applied to wind-energy-conversion systems, Applied Energy, 2010, Article in Press.

[23] D.M. Sable, R.B. Ridley, Comparison of performance of single-loop and current-injection control for PWM converters that operate in both continuous and discontinuous modes of operation, Power Electronics, IEEE Transactions on, vol.7, no.1, pp.136-142, Jan 1992.

[24] M. P. Kazmierkowski, R. Krishnan, F. Blaabjerg, Control in power electronics, Academic Press, London, 2002. 
[25] IEEE recommended practice for grid interface of photovoltaic (PV) systems, IEEE Std. 929, 2000.

[26] M. Ciobotaru, R. Teodorescu, F. Blaabjerg, Control of single-stage single-phase PV inverter, Power Electronics and Applications, 2005 European Conference on, pp.-P.10, 2005.

[27] M. Ciobotaru, R. Teodorescu, F. Blaabjerg, A new singlephase PLL structure based on second order generalized integrator, in Record of IEEE PESC 2006, Jeju, Korea, p. 1511-1516.

[28] M. Liserre, A. Timbus, R. Teodorescu, F. Blaabjerg, Synchronization methods for three phase distributed power generation systems. An overview and evaluation, PESC 2005, Recife, Brasile.

[29] C. Zhang, W. Liu, G. San, W. Wu, A Novel Active Islanding Detection Method of Grid-connected Photovoltaic Inverters Based on Current-Disturbing, Power Electronics and Motion Control Conference, 2006. IPEMC 2006. CES/IEEE 5th International, Vol.3, pp.1-4, Aug. 2006.

[30] M.E. Ropp, M. Begovic, A. Rohatgi, Prevention of islanding in grid-connected photovoltaic systems, Progress in Photovoltaics: Research and Applications, Vol. 7, No. 1, pp. 39-59, 1999. Available: http://www3.interscience.wiley.com/cgi-bin/fulltext/40007275/PDFSTART.

[31] A. V. Timbus, R. Teodorescu, F. Blaabjerg, U. Borup, Online grid measurement and ENS detection for PV inverter running on highly inductive grid, IEEE power electronics letters, Vol. 2, No. 3, pp. 77-82, September 2004.

[32] M. Ciobotaru, V. Agelidis, R. Teodorescu, Accurate and less-disturbing active anti-islanding method based on PLL for grid-connected PV Inverters, Power Electronics Specialists Conference, 2008. PESC 2008. IEEE, pp.4569-4576, June, 2008.

[33] PSIM 7.0 User's Guide (2006), Powersim Inc. 